\title{
Evaluation of Pavement Surface Conditions for Luxor International Airport
}

\author{
S. Fathalla* and A. El-Desouky ${ }^{* *}$
}

\begin{abstract}
:
Egypt has many airports which include millions of square meters of paved runways, taxiways and aprons. These pavements serve a great mix of different aircrafts. Aviation community has a large investment in airport pavements. The main purpose of airfield pavements is to carry aircraft loads conveniently, economically, and safely during its design life. In addition, good ride-quality which permit safe operation of aircraft under all weather conditions is essential for runway and taxiway pavements. Immediately upon completion of construction, airport pavements begin a gradual deterioration which is attributed to several factors. These factors include traffic loads, climate, and others causes due to faulty construction techniques. In addition, inferior materials properties and differential movement of the underlying layers can fasten pavement deterioration and effect pavement performance. Consequently, failure to perform routine maintenance during the early stages of deterioration may result in extensive repairs at a later date. The decision to conduct maintenance works depends mainly on the evaluation of the pavement surface conditions. Some pavement distresses as raveling and weathering could produce loose aggregate particles on the runway surface which cause a serious safety problem. This study aims to evaluate the condition of the pavement surface of Luxor International Airport, Egypt. Field inspection includes determination of the type, severity and extent of all surface distresses and defects. Distresses were observed, assessed and tabulated. The Pavement Condition Index (PCI) technique for airport pavement and contribution of the different distress types were calculated. The computer software Micro PAVER 5.2 was then used to analyse the collected data. The results show that the most effective distresses were depression, raveling and weathering, and longitudinal and transverse cracking.
\end{abstract}

* Egyptian Armed Forces, Egypt.

** Professor, Department of Civil Engineering, Canadian International College, Cairo, Egypt; ah ibrahim@cic-cairo.com 
Other less effective distresses affecting the studied features were bleeding and oil spillage. The results of this study emphasis the importance of conducting periodic evaluation of airfield pavement surface condition upon which a maintenance decision could be taken.

Keywords: airports, pavement condition index, distresses

\section{Background and Methodology}

Rehabilitation of the airport areas is required to maintain a standard serviceability of pavement for commercial operations. Therefore, to understand the reasons for current conditions of pavement surface, a useful evaluation should be conducted to identify different types of pavement distress and link them to a cause [1-3]. Pavement Condition Index (PCI) technique is a simple, convenient and inexpensive way to monitor the condition of pavement surface [4]. The PCI is used to identify the pavement condition based on pavement sections and a number of sample units in each section [4]. The range of PCI is referred to the surface condition; the PCI of 85-100 indicates the pavement condition is good, 70-85 is satisfactory, 55-70 is fair, 40-55 is poor, $25-40$ is very poor, $10-25$ is serious and $0-10$ is failed [4]. Figure (1) shows the PCI rating scales for pavement surfaces [4] and the required maintenance action based on PCI values [5]. generally, pavements with relatively high PCI values requires preventive maintenance operations, such as surface treatments and crack sealing. Major rehabilitation such as an overlay applies when PCI values decrease to certain extent. For relatively lower PCI values, reconstruction may be required. due to the substantial damage to the pavement structure. The figure below illustrates how the appropriate repair type varies with the PCI of a pavement section [5]. In addition, to assess the behavior of pavement, the index of pavement distress should be calculated and studied [6,7]. These indices are fatigue, joint reflection, longitudinal and transverse cracking, slippage, block cracking, bleeding, corrugations, shoving, depression, patching, polished aggregate, potholes, raveling, rutting, stripping, and water bleeding and pumping [6,7]. In this study, the index of pavement distress is used to evaluate the pavement surface for Luxor International Airport. 


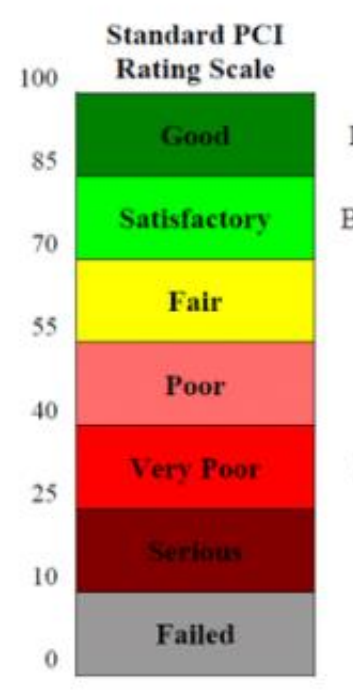

(a)

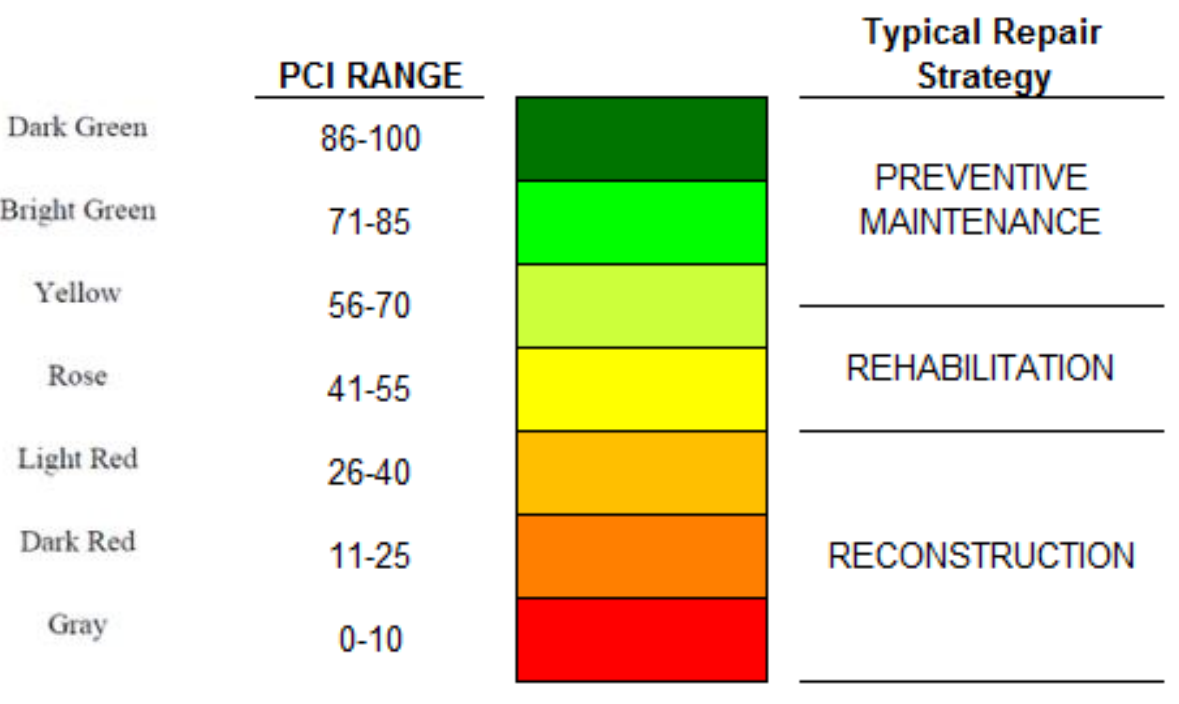

(b)

Fig. 1. (a) Standard PCI Rating Scale [4] and (b) Typical Repair Strategy [5].

Luxor International Airport is one of important airports in Egypt; it is located in Luxor, south of Egypt. Fig. 2 shows the airport plan and sections. The purpose of this study is to evaluate the pavement surface condition of each element of the airfield pavement system. Pavement surface inspection and evaluation is done according to the PCI technique for airport pavement evaluation as outlined by the U.S. Army Corps of Engineers (UFC 3-270-05\&06) and as set forth in ASTM D5340, Standard Test Method for Airport Pavement Condition Index Surveys [8]. The PCI results from a condition survey and a numerical rating of the pavement condition that ranges from 0 to 100. The pavement condition rating is a description of pavement surface condition as a function of its PCI value. Based on PCI values, the rating of pavement surface represents the pavement status.

Detailed visual inspection of distresses/defects manifested on the runway, taxiways and apron surface is conducted as per the PCI procedures. Observations are carried out and recorded for several sample units taken from homogeneous features. These features are defined by dividing the airfield pavements into smaller segments with homogeneous characteristics from the view point of pavement type, pavement condition, pavement structural section, and type of traffic. Each sample unit chosen is individually inspected. The actual inspection is performed by walking over the sample unit by a pavement evaluation expert to measure the distress type, extent, and severity, and record all measured and observed data. Sample units are selected in accordance with guidance 
contained in TM 5-826-6/AFR 93-5 [8]. This is done for a total of 16 distress/defect types for flexible pavements and 15 for rigid pavements. The values of PCI are determined for each sample and then summarized for each feature and each airfield element.

\section{Feature Identification and Sampling}

Airfield Elements: The airport pavements (as shown in Fig. 2) consists of the following main elements: Main runway 02-20; Taxiways including: Main Taxiway (Taxi "A"), connecting Taxiways (Taxi "B" through "J"), Apron Taxiways (Apron Taxiways "D", "F" and "K"), and Apron Taxilanes (1 through 3); and Aprons including: PCC Aprons (the New Apron and the Old Apron), and the isolated AC Apron. These elements are divided into 10 homogeneous features having the same traffic pattern, pavement type, pavement structural section, and overall surface conditions. Fig. 2 shows the division of the airfield into features. Description of these features is given in the following section.

\section{Feature Identification and Description}

According to the normal traffic types using the airfield and pavement type and construction, the runway can be divided into 4 features as follows (see Fig. 2):

i. Feature R01: This section starts from distance 0 to $450 \mathrm{~m}$ measured from the 02 threshold (take-off zone). A total of 8 samples were inspected to represent the condition of this feature.

ii. Feature R02: This section starts from distance 450 to $900 \mathrm{~m}$ (touchdown zone). A total of 8 samples were inspected to represent the condition of this feature. 


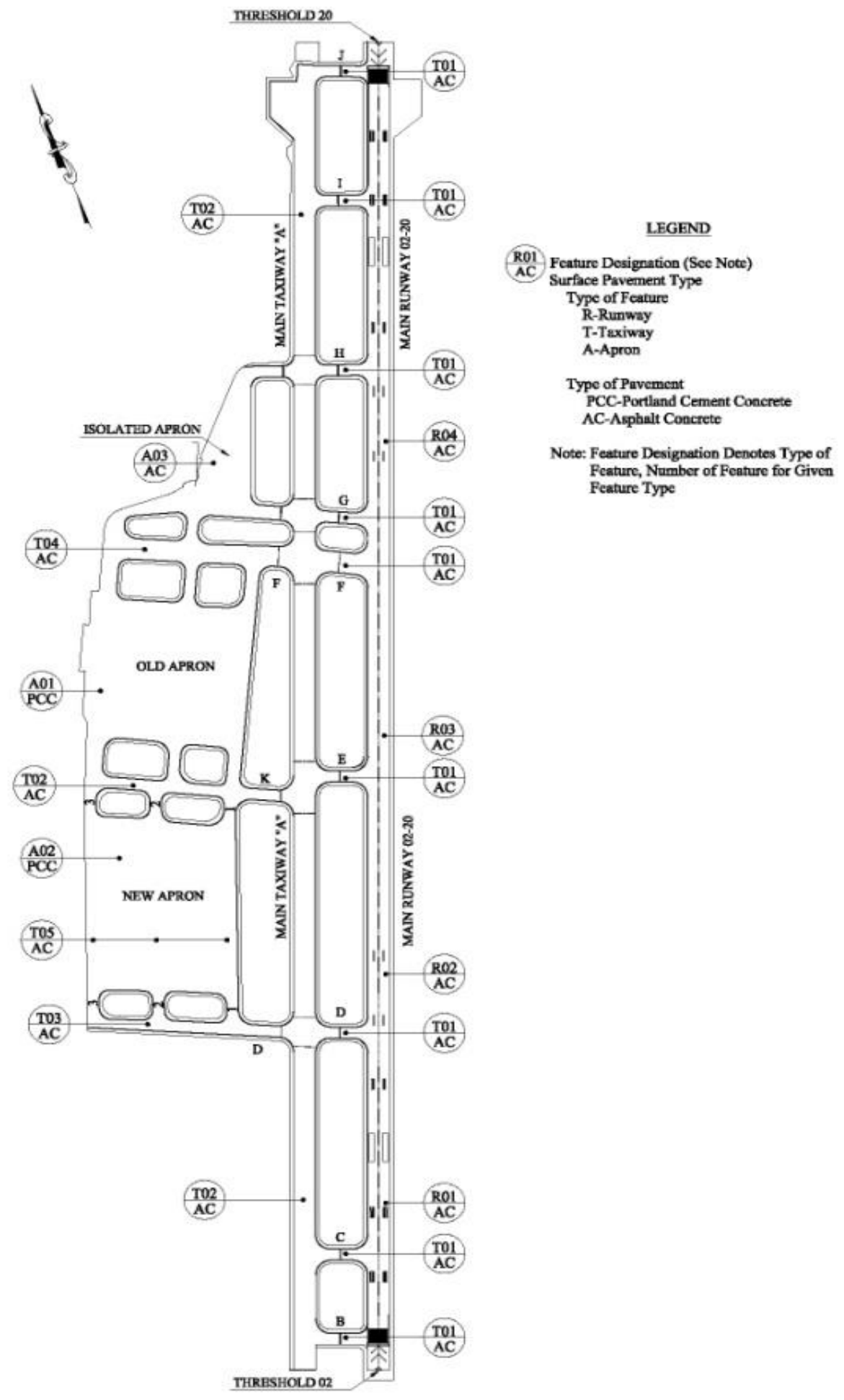

Fig. 2. Feature Identification for Luxor Airfield Pavements 
iii. Feature R03: This section starts from distance 900 to $1800 \mathrm{~m}$. A total of 13 samples were inspected to represent the condition of this feature.

iv. Feature R04: This section starts from distance 1800 to $3000 \mathrm{~m}$. A total of 8 samples were inspected to represent the condition of this feature.

All main runway features are paved using Asphalt Concrete (AC).

According to the normal traffic types using the airfield and pavement type and construction, the taxiways can be divided into 5 features as follows (see Figure 2):

i. Feature T01: Includes all connecting taxiways "B $\sim \mathrm{J}$ ". These taxiways are paved using AC. A total of 9 samples were inspected to represent the condition of this feature.

ii. Feature T02: Includes the whole length of the parallel taxiway "A" and Apron Taxiway " $\mathrm{K}$ ". This taxiway is paved using AC.

iii. Feature T03 and T04 include Apron Taxiway "D" and "F", respectively. These taxiways are paved using AC; and, there are generally in good condition with almost no distresses.

iv. Feature T05: Includes Apron Taxilanes "1, 2, and 3". These Taxilanes are paved using asphalt concrete.

Due to airport operation conditions only Feature T01 was inspected and data were reported.

In addition, according to the normal traffic types using the airfield and pavement type and construction, the apron can be divided into 3 features as follows (see Figure 2):

i. Feature A01: This feature includes the Old Portland Cement Concrete (PCC) Apron ( $325 \times 315$ meters). A total of 16 samples were inspected to represent the condition of this feature.

ii. Feature A02: This feature includes New PCC Apron $(375 \times 315$ meters). A total of 18 samples were inspected to represent the condition of this feature.

iii. Feature A03: This feature includes the extension of the Old AC Apron (the isolated Apron).

Again, Feature A03 was not inspected due to the airport operation conditions

\section{Results and Discussions}

The measured field data on pavement condition were analyzed using the software Micro PAVER 5.2 [9] in order to determine pavement condition index/rating and to analyze observed distresses. The measured distresses information for each of the 80 
sample units representing the different features of the airfield pavements were analyzed separately and then grouped by feature/element for detailed analysis. The data are collected and analyzed to assess the pavement condition. Tables 1 and 2 show a summary of analyses results of pavement condition, rating, and the general cause of the observed distresses. Average PCI value and rating of pavement surface condition for each feature are introduced in Table 1 . The deduct values due to different distress causes are presented in Table2. Tables 3 and 4 present a summary of distress distribution for flexible and rigid pavements, respectively. Figs. 3 and 4 show the contribution of the different distress types in the deduct values for asphalt concrete pavements of runway and taxiways, respectively. While Figs. 5 and 6 show the distribution for old and new aprons made of PCC, respectively.

Table 1. Summary of Pavement Condition by Feature

\begin{tabular}{|c|c|c|c|c|}
\hline \multirow{3}{*}{ Element } & \multirow{2}{*}{ Feature ID } & Pavement & \multicolumn{2}{|c|}{ Pavement Condition } \\
\cline { 4 - 5 } & & Type & PCI & Rating \\
\hline \multirow{3}{*}{ Runway } & R01 & AC & 78 & satisfactory \\
\cline { 2 - 5 } & R02 & AC & 77 & satisfactory \\
\cline { 2 - 5 } & R03 & AC & 85 & satisfactory \\
\cline { 2 - 5 } & R04 & AC & 82 & satisfactory \\
\cline { 2 - 5 } & ALL & AC & 80 & satisfactory \\
\hline Taxiway & T01 & AC & 74 & satisfactory \\
\hline \multirow{2}{*}{ Apron } & A01 & PCC & 37 & very poor \\
\cline { 2 - 5 } & A02 & PCC & 87 & good \\
\hline
\end{tabular}

Table 2. Summary of Cause of Distresses by Feature

\begin{tabular}{|c|c|c|c|c|c|}
\hline \multirow{3}{*}{ Element } & \multirow{2}{*}{ Feature ID } & Pavement & \multicolumn{3}{|c|}{ \% Deduct Points by Main Cause of Distress } \\
\cline { 4 - 6 } & & Type & Load & Climate/Durability & Others \\
\hline \multirow{4}{*}{ Runway } & R01 & AC & 0 & 37.1 & $62.9^{*}$ \\
\cline { 2 - 6 } & R02 & AC & 0 & 35.3 & $64.4^{*}$ \\
\cline { 2 - 6 } & R03 & AC & 0 & 46.9 & $53.1^{*}$ \\
\cline { 2 - 6 } & R04 & AC & 0 & 31.8 & $68.2^{*}$ \\
\cline { 2 - 6 } & ALL & AC & 0 & 39.6 & $60.4^{*}$ \\
\hline Taxiway & T01 & AC & 0 & 51.4 & $48.6^{*}$ \\
\hline \multirow{2}{*}{ Apron } & A01 & PCC & 10.4 & 00.2 & $89.4^{*}$ \\
\cline { 2 - 6 } & A02 & PCC & 4.4 & 17.0 & $78.6^{*}$ \\
\hline
\end{tabular}

* Factors related to Construction and Materials. 
Table 3. Summary of Distress Distribution for Flexible Pavements

\begin{tabular}{|c|c|c|c|c|c|}
\hline \multirow{3}{*}{ Distress Type } & \multicolumn{5}{|c|}{$\%$ of TDV for Element/Feature } \\
\hline & \multicolumn{4}{|c|}{ Runway } & Taxiway \\
\hline & R01 & R02 & R03 & R04 & T01 \\
\hline Bleeding & 1.95 & -- & -- & -- & 0.13 \\
\hline Depression & 70.56 & 75.04 & 64.18 & 76.68 & 42.16 \\
\hline Raveling and Weathering & 27.49 & 20.34 & 31.83 & 23.32 & 17.80 \\
\hline LIT Cracking & -- & 1.36 & - & -- & 21.70 \\
\hline Patching & -- & 3.26 & 3.99 & -- & 3.84 \\
\hline Block Cracking & -- & -- & -- & -- & 10.24 \\
\hline Oil Spillage & -- & -- & -- & -- & 0.76 \\
\hline Polished Aggregate & -- & -- & -- & -- & 3.37 \\
\hline
\end{tabular}

Table 4. Summary of Distress Distribution for Rigid Pavements

\begin{tabular}{|l|c|c|}
\hline \multirow{2}{*}{\multicolumn{1}{|c|}{ Distress Type }} & \multicolumn{2}{c|}{$\%$ of TDV for Element/Feature } \\
\cline { 2 - 3 } & Feature (A01) & Features (A02) \\
\hline Corner Break & 5.52 & 2.41 \\
\hline Long/Trans/Diagonal Crack & 4.02 & 6.56 \\
\hline Durability Crack & 0.08 & -- \\
\hline Joint Sealant Damage & 0.12 & 10.09 \\
\hline Patching & 1.54 & -- \\
\hline Popouts & 7.05 & 9.62 \\
\hline Scaling/Map Crack & 11.75 & 1.39 \\
\hline Settlement/Fault & 31.74 & -- \\
\hline Shrinkage Crack & -- & 0.32 \\
\hline Spalling Joint & 34.17 & 68.96 \\
\hline Spalling (Corner) & 4.00 & 0.65 \\
\hline
\end{tabular}




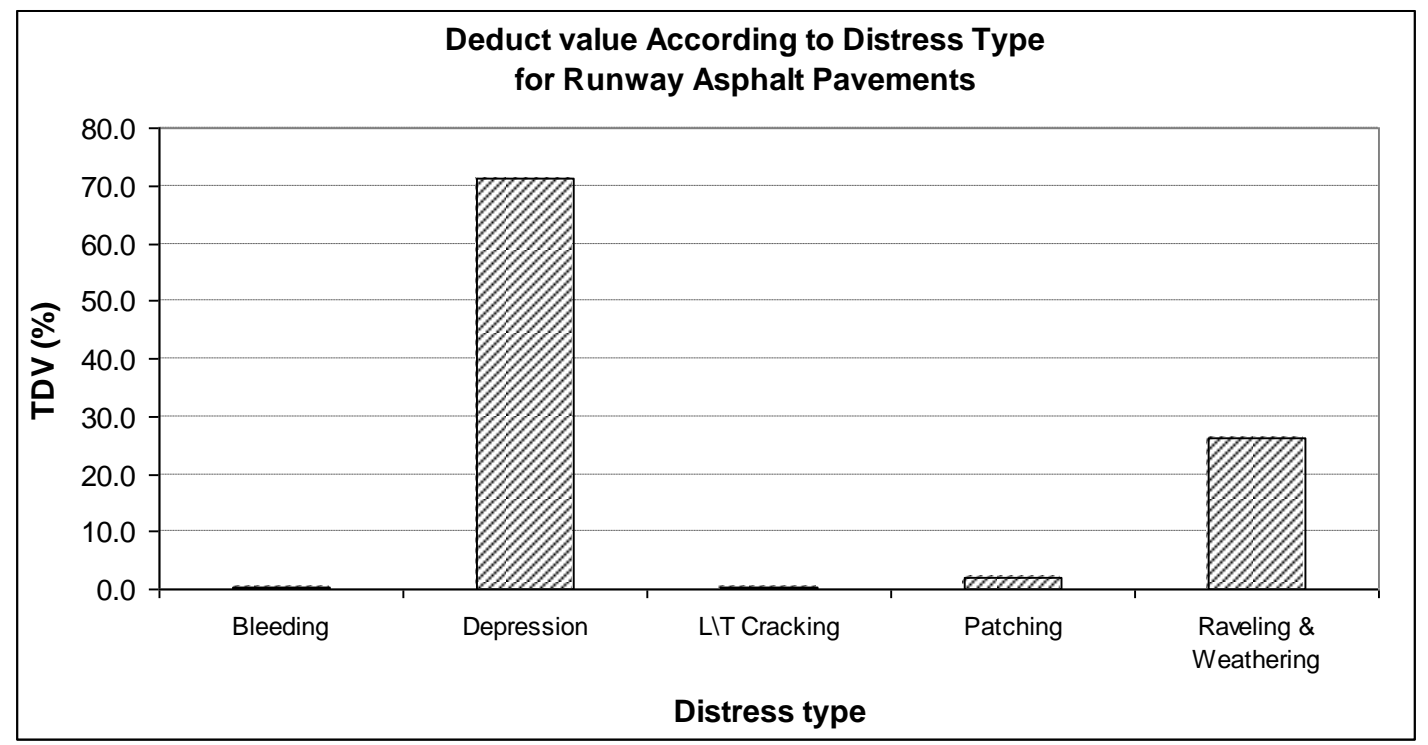

Fig. 3. Distress Contribution in Overall Condition for Runway Asphalt Pavement

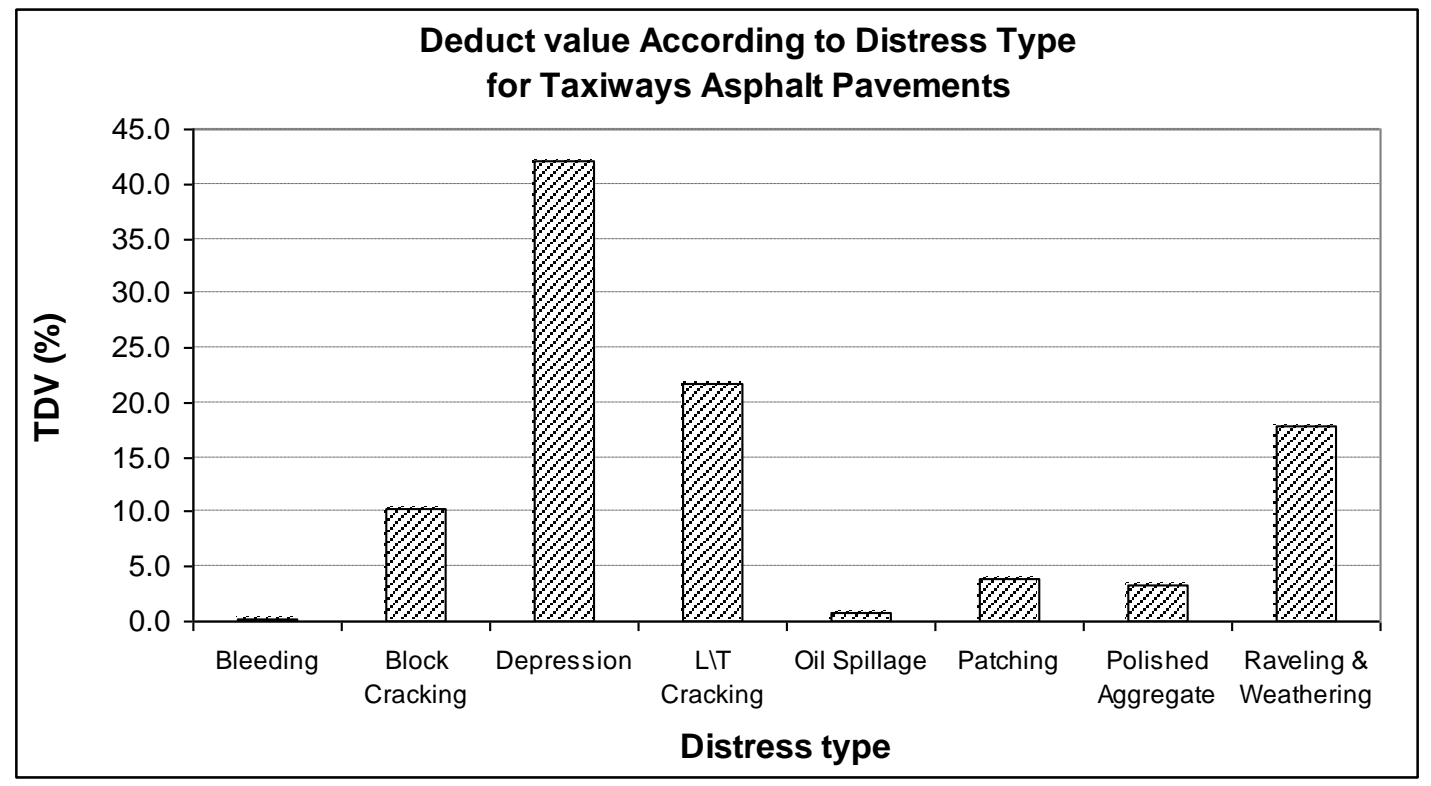

Fig. 4. Distress Contribution in Overall Condition for Taxiways Asphalt Pavement 


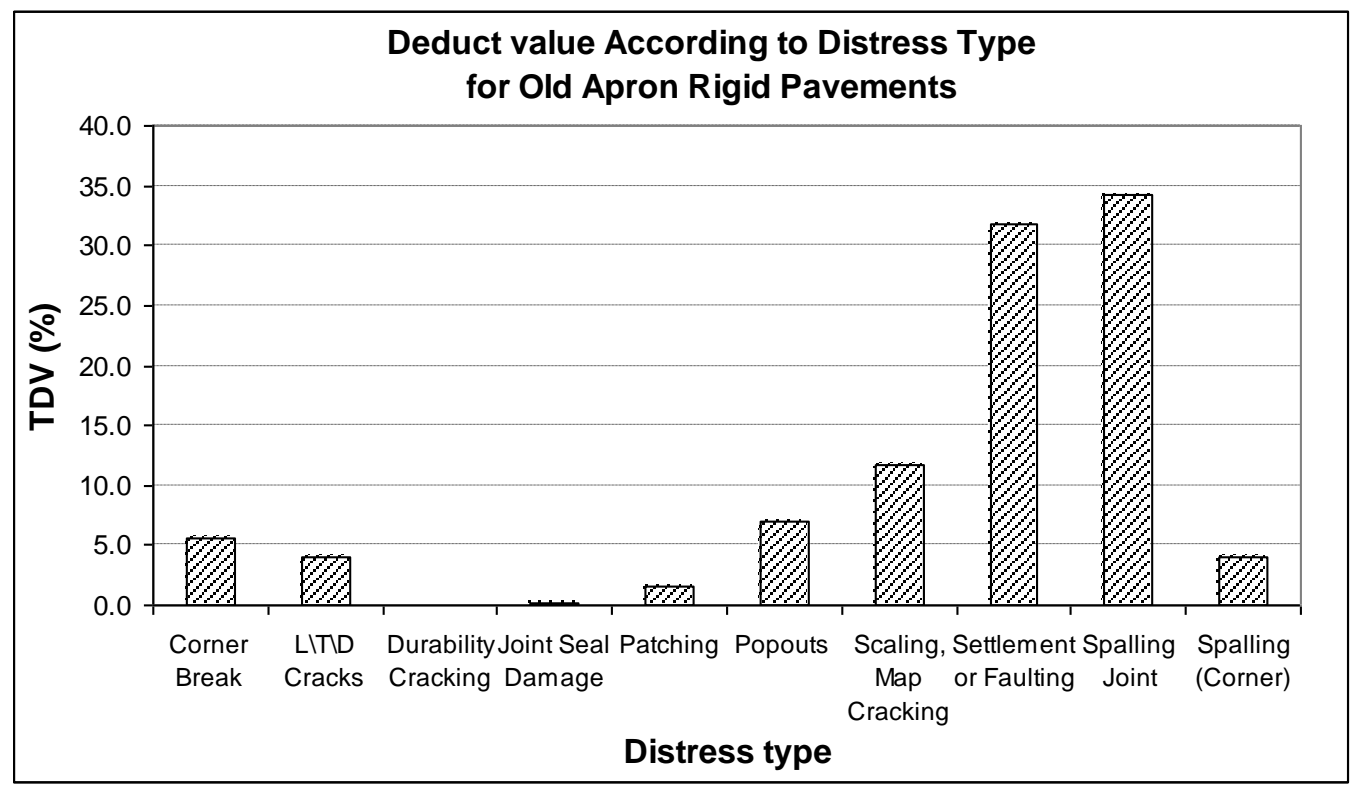

Fig. 5. Distress Contribution in Overall Condition for Old Apron Rigid Pavement

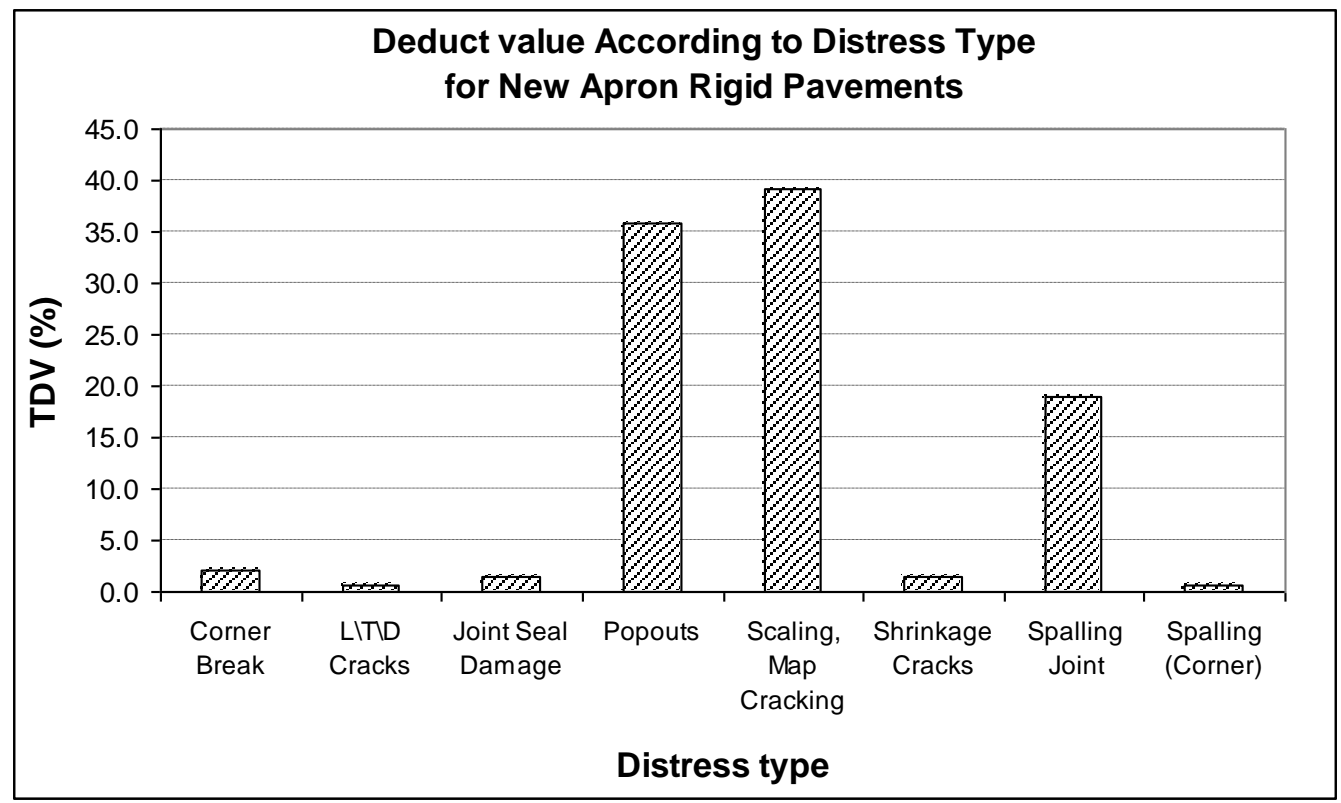

Fig. 6. Distress Contribution in Overall Condition for New Apron Rigid Pavement 
From Tables 1 and 2 and Fig. 3, it can be seen that the runway condition can be presented as follows:

i. Feature R01: PCI was determined to be between 59 and 93 with an average PCI value of 78. The rating of pavement surface was "Fair to Good" and the average rating of this feature was "satisfactory". The most effective distresses were depression and raveling and weathering. These indicate that the main cause of these distresses is others.

ii. Feature R02: PCI values ranged from 50 to 97 with the average PCI value of 77. Surface conditions were "poor to good" with "satisfactory" overall rating. The most effective distresses noticed in this feature were depression and raveling and weathering. Again, the main cause of these distresses can be referred as others.

iii. Feature R03: PCI values ranged from 64 to 98 with an average PCI value of 85 . The overall pavement surface condition of Feature 03 was "satisfactory" where the sample unit ratings were "fair to good". The most effective distresses were depression and raveling and weathering. The main cause of these distresses is also others.

iv. Feature R04: PCI values changed between 65 and 99 and the average PCI value was 82. Pavement surface ratings were "fair to good" and the overall rating was "satisfactory". Same effective distresses as in other runway features were noticed.

For the Taxiways (Feature T01), Tables 1 and 2 and Fig. 4 show that average PCI value of 74 were calculated where PCI values for the evaluated sample units were between 59 to 90 . The pavement surface conditions were "fair to good" with "satisfactory" overall rating. The main distresses noticed were depression, raveling and weathering, and longitudinal and transverse cracking. Other less effective distresses affecting this feature were bleeding and oil spillage. Both Climate/durability and others are causes of distresses appears on the surface of connectors (Taxiways B $\sim \mathrm{J}$ ).

In addition, for the PCC Apron Tables 1 and 2 show that;

i. Feature A01: the PCI values were determined to be between 20 and 74 and the average PCI value was calculated to be 37 . Ratings of different sample units were "serious to good" with an overall rating of "very poor". The most effective distresses were, joint spall, settlement and faulting, scaling and map cracking, and popouts (see Fig. 5). The main cause of these distresses is others. 
ii. Feature A02: Average PCI value was 87 which is the average of PCI values of all sample units in this feature. PCI values ranged between 75 and 96. Pavement surface ratings for different sample units were "satisfactory to good" with "good" overall rating. The most effective distresses noticed were scaling and map cracking, popouts, and joint spall (see Fig. 6). Main cause of these distresses is others.

\section{Overall Evaluation of Pavement Condition}

Main Runway 02-20 is in "satisfactory" condition. The 20 Threshold side seems to be in a slightly better condition. Fig. 3 illustrates the distress distribution for runway flexible pavements. In general, depression is the main distress affecting this runway. Observed depressions are mostly built up during construction (bad leveling both in the longitudinal and transverse directions). Due to the presence of this distress, some sample units were rated as "fair" or even "poor" condition. Also raveling and weathering is another distress covering limited areas of the runway. In the case of Luxor Airport, this distress is mainly due to asphalt mix segregation and bad handling during construction. In addition to the main two distress types discussed above, bleeding, longitudinal and transverse cracking, and patching appeared in some sample units of the runway.

The connecting taxiways are generally in satisfactory condition. Connecting Taxiways "G", "H", and "J" are in "fair" condition. Fig. 4 shows that depression, longitudinal and transverse cracking, and raveling and weathering are the main distress types observed along the connecting taxiways. Block cracking was observed in a wide area of Taxiway "J". All these distresses are the result of difficulty in asphalt mix preparation and handling and consequent environmental effects on the mix. Air traffic load is not a cause for any of the observed distresses.

Table 4. introduces a summary of distress distribution for rigid pavement. These data are shown in Fig. 5 for the old PCC apron. The PCC slabs at the old apron are in "very poor" condition. Joint spall in the form of breakdown of the slab edges within 0.6 meter of the side of the joint is one of the most serious distresses in this area. This condition results from excessive stresses at the joint caused by infiltration of incompressible materials or traffic loads. Also weak concrete at the joint (caused by overworking) combined with traffic loads is another possible cause for this distress. Settlement and faulting in the form of difference of elevation at joints due to upheaval or consolidation of the subgrade soil beneath the PCC slabs is another serious distress 
observed in the old apron. Some of the observed faulting is built up during construction (bad leveling of adjacent slabs). Map cracking is another noticeable distress manifested in this area. This distress is in the form of network of shallow, fine, or hairline cracks which extend only through the upper surface of the concrete. The main reason of this distress is the over finishing of concrete surface. Also popouts in the form of small pieces of pavement that break loose from the surface is another noticeable distress in these PCC slabs. The use of improper aggregates (expansive) is the main reason for this distress. Overall, aging, inferior concrete quality, deferred maintenance of joint seals, and subsequent over stressing due to traffic and climatic changes are the main factors that lead to this serious condition.

The PCC slabs at the new apron are in "good" condition. As shown in Table 4 and Fig. 6 , joint spall, joint sealing damage, and popouts are the main distress types affecting the new apron. Low severity joint sealant damage with high extent is also present in some areas of this apron. Although this distress is currently not causing serious drop in condition, this distress can cause rapid deterioration of these slabs. Inferior aggregate quality, deferred maintenance of joint seals, and subsequent over stressing due to traffic are the main factors causing the observed distresses. Restoration of joint sealants needs to be implemented to prevent further deterioration of this apron.

\section{Conclusions}

The serviceability of Luxor Airport, Egypt, is evaluated and reported in this study. The pavement surface condition is assessed using the visual inspection to determine the pavement condition index (PCI). Based on the results and analysis presented in this study, the following could be concluded;

1. The main factor for the distresses is the construction materials and methods. Moreover, the main distresses for the runway and taxiways are depression, raveling and weathering, and longitudinal and transverse cracking. While for the apron, the main distresses are spalling joint, settlement, joint sealing damage, and popouts.

2. Although the overall rating of the main runway 02-20 is "satisfactory", some sample units were found in poor and fair conditions. Cautions should be paid to conduct periodic evaluation of the runway surface conditions. In addition, preventive maintenance should be performed regularly.

3. Precautions should be taken to prevent asphalt mix segregation and to allow good leveling and handling during runway constructions. 
4. The overall rating for the connecting taxiways is "satisfactory". However, three connectors have "fair" rating. In addition to the main distresses mentioned above, block cracking was observed in a wide area of Taxiway $\mathrm{J}$.

5. For the apron Feature 01 the rating of pavement surface condition is "very poor" while rating is "good" for Feature 02.

\section{References}

[1] R. Company, "Pavement surface evaluation and rating study - ( PASER )," 2014.

[2] M. of C. Aviation, "Air balloon burning and falling accident while on a touristic trip at the western side of Luxor City, Egypt," 2013.

[3] K. H. Mustafa, M. A. Aziz, M. Rosli, A. A. Zaini, and M. N. M. Warid, "A review on crack relief layer (CRL) in roads and highways," J. Teknol., vol. 78, no. 7-3, pp. 45-52, 2016.

[4] A. A. S. Fareed M.A. Karim, Khaled Abdul Haleem Rubasi, "The road pavement condition index ( PCI ) evaluation and maintenance : A case study of Yemen," Organ. Technol. Manag. Constr., vol. 8, pp. 1446-1455, 2016.

[5] Washington 2018 IDEA, Pavement inspection, Overview [Online]. Available: https://www.appliedpavement.com/hosting/washington/pavement-inspection/pcireview/overview.html. [Accessed: 18-Feb-2019]

[6] F. Department of Transportation, "Airfield pavement inspection reference manual," 2010.

[7] S. Erlingsson, "Failure modes in pavements: Flexible pavement distress modes," $K T H, 2013$. [Online]. Available:

https://www.kth.se/social/upload/5149e50df27654634ecd1034/Pavement. [Accessed: 04-Aug-2018].

[8] USA-Army, "UFC 3-270-01 O\&M MANUAL: Asphalt and concrete pavement maintenace and repair," 2018. [Online]. Available:

https://www.wbdg.org/ffc/dod/unified-facilities-criteria-ufc/ufc-3-270-01. [Accessed: 10-Aug-2018].

[9] Micro PAVER - A Pavement Management System, Version 5.2 User's Guide", U.S. Army Corps of Engineers, Construction Engineering Research Laboratory (CERL), Champaign, Illinois, United States Government, 2004. 